\title{
Use of the Methodology of Network Thinking for a Fatigue Criteria Investigation Based on the Example of Mining Companies
}

\author{
Marcin BUTLEWSKI, Grzegorz DAHLKE, Milena DRZEWIECKA-DAHLKE, Krzysztof HANKIEWICZ, Adam GÓRNY, Brigita GAJŠEK
}

\begin{abstract}
In the paper the factors of workers fatigue were tested by applying network thinking methodology supported by statistical analysis to determine the nature of individual factors for the fatigue management system development. Analysis of the distribution of factors along the intensity map allowed their classification into individual interaction categories, describing directions for miner fatigue management. Active factors were discovered which are: Elevated temperature, Noise and vibration, Oxygenpoor air and mining gases, High humidity, Poor work organization. Critical factors for fatigue management were: Poor technical condition of equipment and Long and timeconsuming approach to headings.
\end{abstract}

Keywords: fatigue factors; fatigue management; mine; miners; network thinking; safety

\section{INTRODUCTION}

Fatigue is a natural consequence of work performed under certain conditions and time. The significance of fatigue in the workplace increases along with the impact it has on the safety of the employee and on others. Assessment and management of fatigue is a complex process because it requires a determination of the impact of a number of different factors whose influence will vary among individuals (due to age, physical fitness, individual predisposition in interactions with many factors). For this reason, there is a need for methods of an aggregate assessment of fatigue that will be useful in management.

\section{PROBLEM DESCRIPTION}

Fatigue is usually defined by: exhaustion as a result of undertaken effort (physical or mental) [1], reduced energy reserves of cells or an entire system [2], or feeling reluctant (or unwilling) to be active [3], however in each situation fatigue will lead to a lower efficiency at work, thereby increasing the risk of errors. Predictive models enable the prediction of the risk of fatigue, but they require the monitoring of a number of phenomena influencing fatigue and the selection of the respective regression model. Such research is carried out extensively in the case of fatigue in the setting of low physical and mental effort (motor vehicle drivers, airplane pilots, during long night shifts). Fatigue arising in such conditions, which results in the loss of consciousness of an employee (sleep), can be predicted based on heart rate measures such as the standard deviation of RR intervals (SDRR), zero-crossings and standard deviations along the semi-major axis (SD2) in a Poincare plot [4]. Fatigue is also diagnosed based on voice (when communicating with the tested driver) $-83.8 \%$ recognition rate [5]. EEG equipment is used to assess signs of fatigue and can with a high accuracy (almost 100\%) detect fatigue states, however, it is not possible to use it to draw conclusions about the rise of fatigue or preceding intermediate states [6].

Interest in fatigue management is particularly evident in areas of human activity where the consequences of even the smallest errors due to fatigue can be tragic. One such area is certainly bituminous coal mining, which both in
Poland and around the world is subject to special supervision because of the threat to life involved in underground workings $[7,8,9,10]$. This situation arises due to the specific working conditions in this sector and is associated with the occurrence of virtually all natural hazards, the avoidance of which requires employees to have a significant level of psychomotor performance [11, 12 ], which can be achieved by managing fatigue. The need for aggregation of many variable factors, conditions restricting the use of the full spectrum of available tools by employees fatigued due to the harsh working environment (underground coal workings), as well as the need to perform strenuous manual labour, brought about the need to apply a model quite different from the aforementioned ones. The authors decided to identify the factors affecting fatigue and to apply network thinking methodology supported by statistical data to determine the nature of individual factors responsible for fatigue and to propose a model of miner fatigue management.

\section{RESEARCH METHODS}

Analysing the broad issue of fatigue in mining facilities, the authors identified and verified the basic criteria influencing fatigue in miners. A simple standardized interview of a selected population, as a frequently preferred subjective technique [13], was used to determine the subjective importance of various criteria. Interviewing was conducted among miners employed in Polish bituminous coal mines. The miners were supposed to indicate the level of impact a given factor has on fatigue according to the Likert scale of 1-5 (how important this factor is in the development of miner fatigue). The 155 completed questionnaires were put under further statistical analysis. It enabled the selection of those deemed most important. In order to specify a classification of the importance of criteria with a role in fatigue management, the network thinking method was used. As a result of employing this method, a set of actions (scenarios) is obtained that indicate which decisions need to be made in order to reduce the detrimental impact of fatigue-inducing factors on employees. This solution is universal, but concerns only the specific nature of the examined mines. 
First, the problem, a complex process that requires a multi-faceted perspective on the analysed issue, is defined [14]. A description of the main problematic situations is presented in Fig. 1.

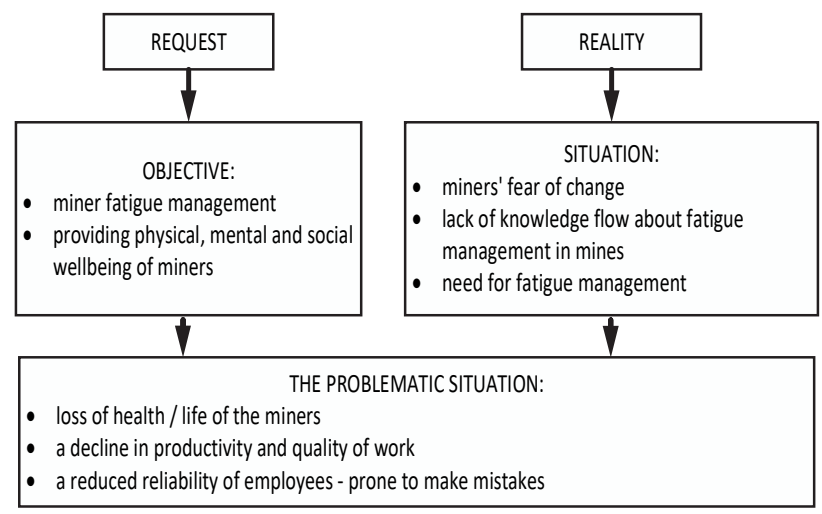

Figure 1 The emergence of problematic situations (own work)

While conducting research in mining facilities, it was apparent that fatigue criteria were not considered in the management process. This pertains to both the organization of mining and transportation activities as well as investigations into indirect causes of workplace accidents. Fatigue-inducing factors' influence leads to a decrease in miner reliability [15-17] and, consequently, increases the tendency to make errors, allowing the hypothesis that they are essential in describing the origin of accidents caused by employees.

The next step of analysis includes defining the stakeholders - the people and institutions that influence the improvement of the fatigue management system in mines. They can be divided into two basic groups - those directly associated with the mining facility (owners, management, employees and the micro-environment: customers, suppliers, competitors) and those unrelated to it directly, but that have an impact (macro-environment: legal, technological, economic, social, demographic and political environment, e.g. State Mining Authority, Central Mine Rescue Station, District Mine Rescue Stations, Central Mining Institute, etc.) [17]. The description of that step was omitted in the paper due to space limitation.

\section{ANALYSIS OF INTERACTIONS 4.1 Characteristics and Selection of Fatigue Factors}

Developing a solution to the problematic situation is conducted in accordance with each step in network thinking methodology. First, miner fatigue was identified as the main factor to be examined. Next, the main factors directly affecting fatigue were described. In order to limit the number of factors, statistical analysis of the results of criteria importance indicated by the miners was performed. The analysed factors and their selected statistical values are presented in Tab. 1.

Table 1 Analysed factors and their selected statistical values (own work)

\begin{tabular}{|c|c|c|c|c|}
\hline No. & Factor & Mean & SD & Kurtosis \\
\hline 1 & Absence of natural daylight & 2.34 & 1.26 & -0.62 \\
\hline 2 & Discomfort resulting from having to work in confined spaces & 2.48 & 1.25 & -0.83 \\
\hline 3 & High humidity & 2.94 & 1.20 & -0.85 \\
\hline 4 & Elevated dust levels & 3.36 & 1.30 & -1.02 \\
\hline 5 & Oxygen-poor air that is contaminated with mining gases & 3.18 & 1.30 & -1.22 \\
\hline 6 & Continuous air circulation (drafts) & 2.48 & 1.28 & -0.91 \\
\hline 7 & Changes in barometric pressure & 1.71 & 1.04 & 1.21 \\
\hline 8 & Frequent changes in work locations & 2.29 & 1.25 & -0.82 \\
\hline 9 & Water leaks or condensation on heading roof & 2.27 & 1.20 & -0.64 \\
\hline 10 & Inclinations of seams and the headings made in such seams & 2.26 & 1.14 & -0.44 \\
\hline 11 & Noise and vibration generated by machinery & 3.35 & 1.18 & -0.67 \\
\hline 12 & Elevated temperature and the need to perform strenuous manual labor & 3.71 & 1.19 & -0.58 \\
\hline 13 & Heavy traffic confined to a small number of tight headings & 2.72 & 1.32 & -1.04 \\
\hline 14 & Perceived threat to life & 2.92 & 1.65 & -1.62 \\
\hline 15 & Commute time (daily to work) & 1.99 & 1.20 & 0.17 \\
\hline 16 & Commute at the beginning and end of each shift - long and time-consuming approach to headings & 2.92 & 1.36 & -1.14 \\
\hline 17 & Scope of responsibilities & 2.63 & 1.32 & -1.05 \\
\hline 18 & Shift work & 2.04 & 1.17 & -0.63 \\
\hline 19 & Working too many hours & 2.02 & 1.07 & 0.34 \\
\hline 20 & Boring, repetitive tasks & 1.93 & 1.07 & -0.21 \\
\hline 21 & Relationship with management & 2.28 & 1.29 & -0.84 \\
\hline 22 & Relationship with co-workers & 1.86 & 1.33 & 0.43 \\
\hline 23 & Poorly organized work (downtime, improper allocation of tasks) & 2.86 & 1.30 & -1.12 \\
\hline 24 & Technical condition of equipment & 3.47 & 1.38 & -0.99 \\
\hline 25 & Time pressure & 2.57 & 1.34 & -1.22 \\
\hline 26 & Lack of visible results of work & 2.17 & 1.30 & -0.67 \\
\hline 27 & Workload outside of the mine & 1.64 & 1.07 & 1.54 \\
\hline
\end{tabular}

Nine factors were selected for further analysis - ones that were to the greatest extent indicated by miners as important in influencing fatigue. Here the Pareto principle was employed, since it was considered that the number of factors over $30 \%$ would considerably complicate proceedings while only marginally explaining miner fatigue. Additionally, standard deviation and kurtosis were calculated, the low value of the latter indicates a high similarity in miners' assessments (answers were concentrated around the mean value).

\subsection{Methodology of Network Thinking}

The methodology of the thought process was developed in Switzerland Gomez, Probst and Ulrich. It was first applied in the late eighties of the last century. It is based on seven basic principles of [18]:

- whole and parts, based on the notion that each system is part of a larger whole, which can also be a system; 
- networking, considering interrelations and the occurring feedback, knowledge of which is crucial to understand the whole;

- openness, which requires the assumption that there is a completely autonomous system that does not need to adapt to the environment;

- complexity, which determines the ability to function in a dynamic environment, with the simultaneous presence of a difficulty of forecasting the future;

- order, resulting from the simultaneous connection of parts present in the network and their inclusion in the structure based on the adopted model of conduct;

- guidance, based on the system's ability to self-control (influencing the system in order to achieve the objective) and regulation (adjusting the system to the designated path);

- progress, associated with the impact the system's members and environment have on the meaning and purpose of the system.

While conducting research, the methodology of network thinking was recognized as a tool for objectively identifying the analysed situation and for indicating the factors responsible for the obtained effect. The applied methodology is based on a holistic approach to solving the given problem. This requires an analysis of an often complex network of connections. Conducting research using the network thinking method required the identification of the interactions existing between factors. For this purpose, the following were specified:

- type of interaction (assuming the possibility of oneway and two-way interactions);

- intensity of interaction, using a four-point scale of assessment (assuming 0 - no interaction, 1 - low level of interaction, 2 - high level of interaction, 3 - very high level of interaction);

- time of interaction, described by identifying the time horizon, or the time by which we expect the interaction to have an impact, assuming a short-term time horizon $\mathrm{S}$ (up to 6 months), medium-term M (6 to 12 months) and long-term L (over 12 months).

The designated values describing the intensity of interaction are supplemented with an indication of the direction of impact, assuming:

- $\quad$ "+ sign, in the presence of a directly proportional impact,

- $\quad$ "-" sign, in the presence of an inversely proportional impact.

The results of the conducted analysis are presented in the influence matrix in Tab. 2.

Table 2 Influence matrix

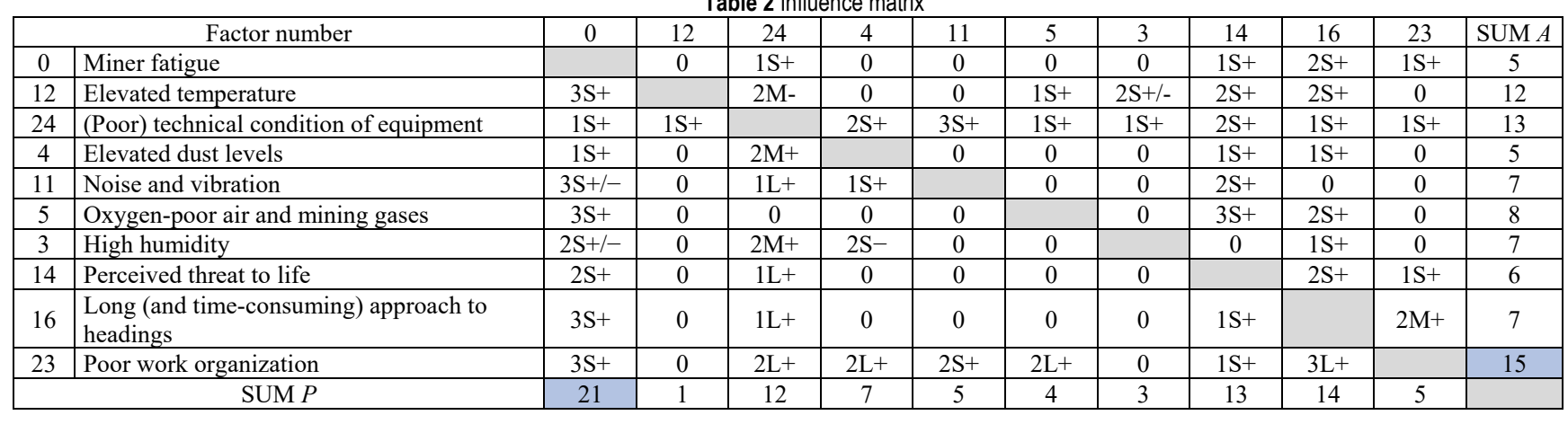

The designated impact indicators made it possible to describe the individual factors, assigning them to one of four groups [19]:

- active factors, which have a large impact on other elements, but are themselves weakly influenced (factors are characterized by a large sum $A$ value);

- passive factors, which have a small impact on other elements, but are themselves strongly influenced (factors are characterized by a small sum $A$ value);

- critical factors, which have a large impact on other elements, and are also themselves strongly influenced (factors are characterized by a large sum $P$ value);

- idle factors, which have a small impact on other elements, and are also themselves weakly influenced (factors are characterized by a small sum $P$ value).

The classification of factors was performed based on a prepared intensity map, which allows for their interpretation. A factor's position on the intensity map is determined by the designated value $A$ (describing the intensity of interaction) and the value $P$ (describing the reactivity of the factor) [19]. Before determining the factor's position, it is important to designate the dividing lines (borders) of the intensity map. The designation creates four fields, characterizing the types of factors. The easiest way to obtain the division is to use half of the maximum values of $A$ and $P$ [20]. With this assumption, the obtained value $A=15: 2=7.5$ and the value of $P=21: 2$ $=10.5$. This designation of the dividing line has been a subject of discussion among experts, who ultimately agreed that the division will be assumed as an average of the sum of parameters $A$ and $P$, or $A=6.33$ and $P=8.18$, which, when rounded down, corresponds to $A=6$ and $P=$ 8. The consensus moved in favour of this assumption thanks to:

- a thorough analysis performed of factors lying on the borders of the intensity map,

- the need for a clear assignment of marginal factors to one category.

The intensity map prepared on the basis of the above assumptions is presented in Fig. 2.

Analysis of the distribution of factors along the intensity map allowed their classification into individual interaction categories, describing directions for miner fatigue management (Tab. 3). 
Table 3 Interpretation of factors

\begin{tabular}{|c|c|c|}
\hline & & \\
\hline GROUP & FACTORS & \multirow{10}{*}{$\begin{array}{l}\text { CONCLUSIONS } \\
\text { Active factors are those which can be controlled in order to achieve improvement in miner fatigue } \\
\text { management. They have a large impact on other elements, but are themselves weakly influenced. Some of the } \\
\text { identified factors result from natural causes, such as the temperature of the rock mass, methane content in coal } \\
\text { seams, wetness of workings. One can influence the working environment parameters and the miners' thermal } \\
\text { perception shaped by these factors, but it would significantly raise the costs of production using traditional } \\
\text { methods. During the study, a significant proportion of respondents selected poor work organization, which } \\
\text { leads to a low extraction efficiency, increasing fatigue and frustration, and thus it also represents the } \\
\text { psychosocial impact. } \\
\text { The following are examples of proposed actions for active factors: } \\
\text { Ad. 12. Check the employee's thermoregulatory efficiency; Adjust energy expenditure. } \\
\text { Ad. 11. Check the effectiveness of personal protective equipment; Perform an acoustic analysis - infrasonic } \\
\text { and ultrasonic components; Refer employee for an audiometric examination - determine noise sensitivity. } \\
\text { Ad. 5. Adjust energy expenditure; Extend breaks; Check the efficiency of ventilation systems. } \\
\text { Ad. 3. Adjust energy expenditure. } \\
\text { Ad. 23. Establish a lottery system of rotating daily responsibilities based on a competence profile. }\end{array}$} \\
\hline \multirow{9}{*}{ 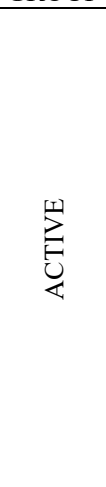 } & 12. Elevated temperature & \\
\hline & & \\
\hline & 11. Noise and vibration & \\
\hline & & \\
\hline & $\begin{array}{l}\text { 5. Oxygen-poor air and } \\
\text { mining gases }\end{array}$ & \\
\hline & & \\
\hline & & \\
\hline & & \\
\hline & 23. Poor work organization & \\
\hline \multirow{3}{*}{ 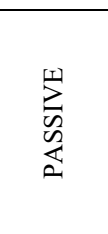 } & 0. Miner fatigue & \multirow{3}{*}{$\begin{array}{l}\text { These criteria can be strongly influenced by other factors, but they behave passively (have a small impact on } \\
\text { other elements). } \\
\text { Fatigue itself does not have an impact on many factors (e.g. fatigue does not influence noise or temperature, } \\
\text { etc.). Changing other factors can ultimately affect fatigue. Similarly, in the case of perceived threat to life - } \\
\text { these factors can be influenced only indirectly by others, particularly those from the active and critical groups. } \\
\text { Fatigue, decreasing employee reliability, will influence the accident rate, which often comes with a } \\
\text { deterioration in the condition of technical equipment, increasing levels of dust, noise and vibration. }\end{array}$} \\
\hline & & \\
\hline & 14. Perceived threat to life & \\
\hline 罣 & 4. Elevated dust levels & $\begin{array}{l}\text { These factors belong to idle group, which means that they have a small impact on other factors, and are also } \\
\text { themselves weakly influenced. }\end{array}$ \\
\hline \multirow{2}{*}{ 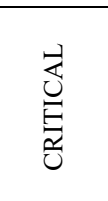 } & $\begin{array}{l}\text { 24. (Poor) technical } \\
\text { condition of equipment }\end{array}$ & \multirow{2}{*}{$\begin{array}{l}\text { These factors are key in the performed analysis. They to the greatest extent influence the level of miner } \\
\text { fatigue. These factors have a large impact on other factors, and are also themselves strongly influenced. They } \\
\text { are an expression of the will of management to take action. One of the main problems in Polish mines is the } \\
\text { length of time needed to reach mine workings due to the failure to build vertical transport shafts. Both of these } \\
\text { factors testify to insufficient investment into technical infrastructure, which is very expensive and significantly } \\
\text { affects profits/losses generated by the mines. }\end{array}$} \\
\hline & $\begin{array}{l}\text { 16. Long (and time- } \\
\text { consuming) approach to } \\
\text { headings }\end{array}$ & \\
\hline
\end{tabular}

PASSIVE

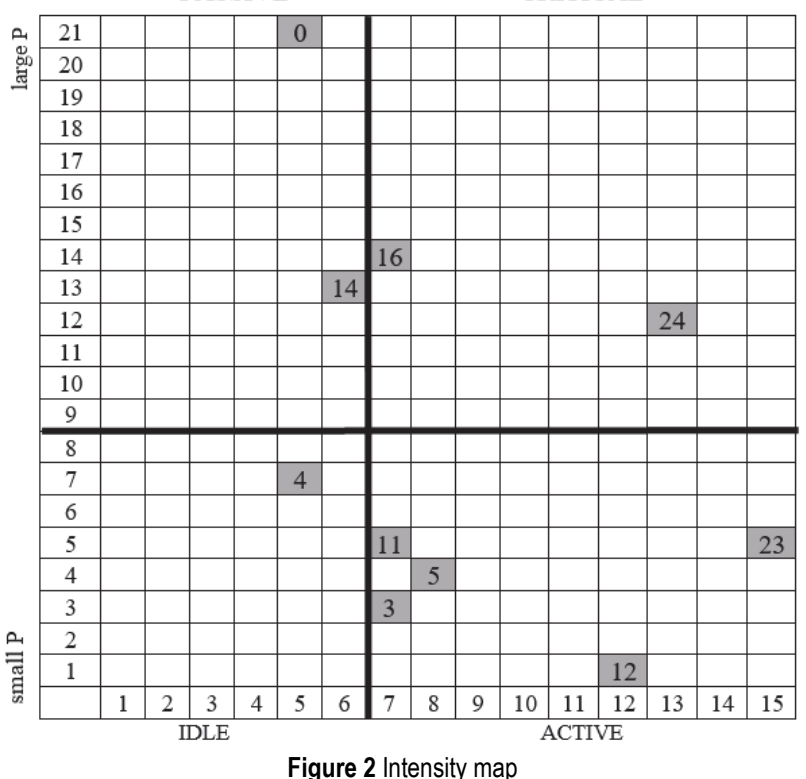

The applied tool made it possible to analyse the factors influencing miner fatigue. In the setting of a dominance of active and critical factors, we may assume that by altering their properties we can influence the existing conditions. It is expected that utilizing only passive and idle factors will bring about negligible changes in the system [21].

\section{MODEL OF MINER FATIGUE MANAGEMENT}

The conducted analysis of the problem identified actions that are possible to implement, and necessary to enact changes in fatigue management for people employed in the mining industry. These changes can be described as a need to enable the employee's ability to perform work [22].

The opportunities to enact change are characterized by fatigue factors, influencing a miner's operation in the work environment. These opportunities are described by [23] manageable factors, unmanageable factors, early warning factors (indicators), feedback and feedforward.

Due to the nature and method of implementing fatigue management it is assumed that of importance are manageable factors, as they indicate whether actions are in accordance with the objectives, as well as indicators, which should be used to evaluate the efficiency and effectiveness of undertaken actions. A simplified management model, based on these aspects, is presented in Fig. 3.

General idea of the fatigue management system must be an anticipation and prevention of potentially dangerous events caused by worker fatigue and resulting in threat to safety of employees and property. For that purpose, the Early warning factors subsystem should be used as a source of information on factors negatively affecting the workload of the employee. This subsystem contains both objective technical and subjective indications. Among the technical, important factors of an employee's workload, for example: high demanding work profiles, the probability of damage to certain machine components (lambda coefficients), the level of used efficiency of mining units, production bottlenecks. Organizational Early warning factors will be the absence of employees employed in specific positions, the density of individual mining teams. An equally important group of factors in the system of recognizing early signs of fatigue will be the subjective assessments of employees themselves. Especially for them, the decisionmaking system will play a large role, whose role will be to transform information of varying weights into a decision option that is useful for decision maker. Of the various 
possible decision algorithms, the system authors decided to use Gray decision making (GDM) [24]. An important advantage of GDM is the use of incomplete and noisy information we are dealing with in the subjective assessments of certain factors causing fatigue. The result of GDM is the assignment of employees to a specific group (4 groups were used in the original system), which allows the decision-maker to choose a specific scenario of action. If an employee is qualified to the highest group, it is recommended to take immediate action, but their scope must be possible due to maintaining production capacity mining. One of the basic decision-making tools in the system is employee relocation in accordance with the competence profile. This required building a competence matrix and developing rules for transition between positions for individual employees. A practical function of the decision system may therefore be to determine the method of rotation of employees from more to less loaded positions. This is how fatigue management system can be briefly described.

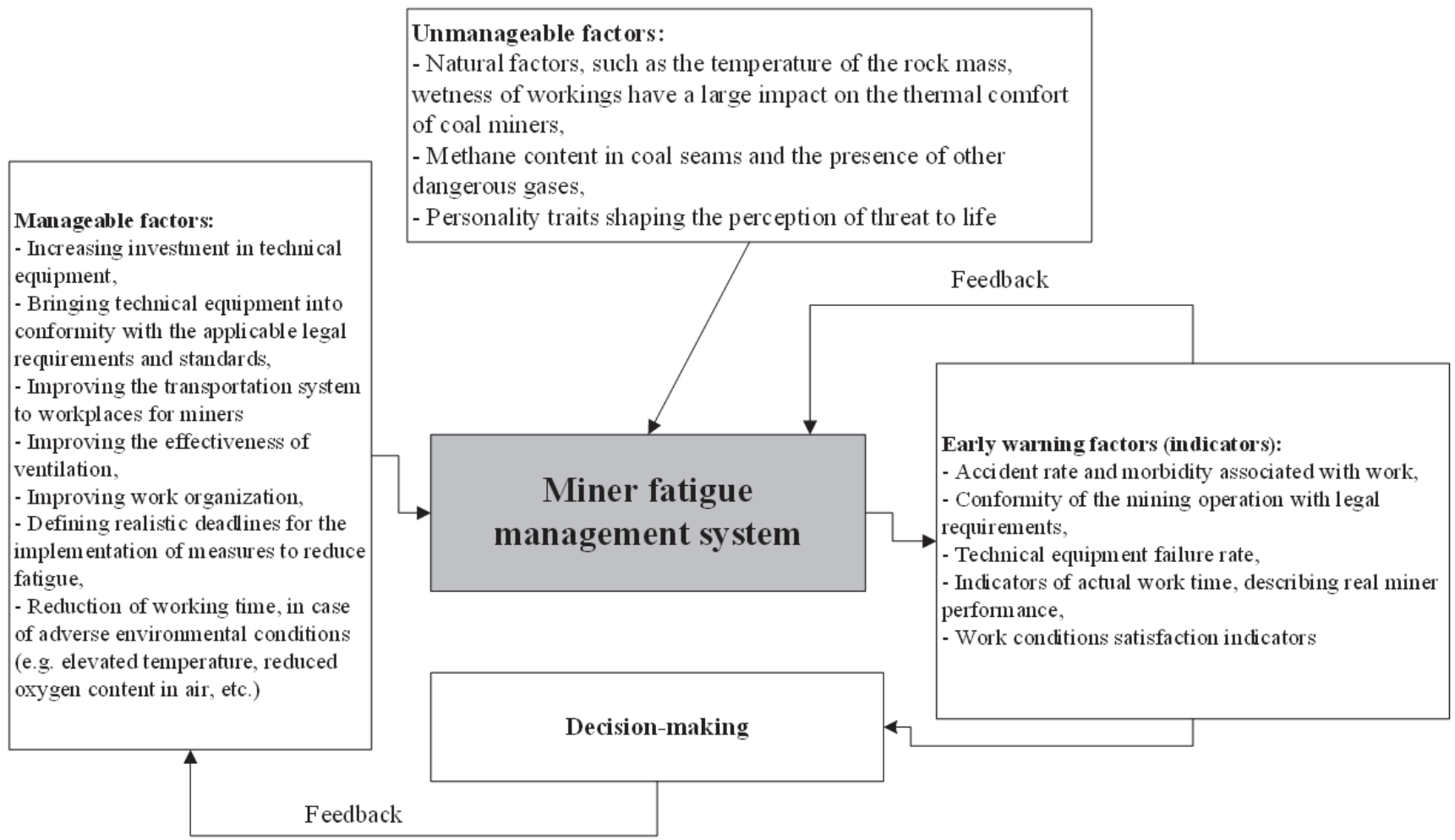

Figure 3 Model of miner fatigue management

A separate aspect of the considerations is the financial implications of changes in the work environment. This topic is interesting both from a scientific point of view and due to practical aspects. The costs of implemented changes in terms of improving working conditions and proactive measures to reduce employee fatigue are usually compared with improving work quality, reducing the number of accidents and improving productivity [25]. Positive effects are observed, however, over a long period of time. Payback period may vary from less than year up to 6 years [26].

\section{CONCLUSIONS}

In the current conditions of functioning of business entities, an important role is played by "soft" actions, which not only influence work productivity and effectiveness but also determine a company's position on the market. The implementation of a fatigue management system should be included in these actions.

Fatigue management in mining companies should be treated as an essential social need. An important role is attributed to management responsible for the implementation of the management system and for providing the resources necessary for the proper functioning of the system. The specificity of the present problem indicates the need for a multifaceted analysis and the application of a variety of technical and organizational measures. These actions can be categorized as manageable and unmanageable factors.

It should also be noted that actions concerning individual factors should be in some degree treated individually. Fatigue management is in fact a process, which results in the welfare of an individual miner. A fatigue management system based on this principle should therefore provide the opportunity to: identify the initial state of fatigue and decision-making on allowing to work, interpret individual biological results of fatigue and recognize undesirable states for the given miner, consider personal opinions (conducted user surveys) and data regarding miners (e.g. height, weight). Only integrated measures of improvement in manageable and most impactful factors of fatigue and a systematic individualized approach give rise to the possibility of achieving real results in managing fatigue and improving safety.

\section{REFERENCES}

[1] Jethon, Z. (1977). Fatigue classification system. In: Z. Jethon (Ed.), Zmęczenie jako problem współczesnej cywilizacji (p. 46). Warszawa: Państwowy Zakład Wydawnictw Lekarskich. 
[2] SoamesJob, R. F. \&Dalziel, J. (2001). Defining fatigue as an condition of the organism and distinguishing it from habituation, adaptation and boredom. In: P. A. Hancock, \& P. A. Desmond (Eds.), Stress, workload and fatigue (p. 471). New Jersey: CRC Press.

[3] Lerman, S. E., Eskin, E., Flower, D. J., George, E. C., Gerson, B., Hartenbaum, N., \& Moore-Ede, M. (2012). Fatigue risk management in the workplace. Journal of Occupational and Environmental Medicine, 54(2), 231-258. https://doi.org/10.1097/JOM.0b013e318247a3b0

[4] Heinze, C., Trutschel, U., Schnupp, T., Sommer, D., Schenka, A., Krajewski, J., \& Golz, M. (2009). Operator Fatigue Estimation Using Heart Rate Measures. In: O. Dössel, \& W. C. Schlegel (Eds.), PROCEEDINGS of the Fifth International Driving Symposium on Human Factors in Driver Assessment, Training and Vehicle Design(pp. 110117).Heidelberg, Springer: Berlin. https://doi.org/10.1007/978-3-642-03882-2_248

[5] Krajewski, J., Trutschel, U., Golz, M., Sommer, D., \& Edwards, D. (2009). Estimating Fatigue from Predetermined SpeechSamples Transmitted by Operator Communication Systems. In: Proceedings of the Fifth International Driving Symposium on HumanFactors in Driver Assessment, Training and Vehicle Design, (pp. 468-474). Iowa City, IA: Public Policy Center, University of Iowa. https://doi.org/10.17077/drivingassessment.

[6] Trejo, L. J., Knuth, K., Prado, R., Rosipal, R., Kubitz, K., Kochavi, R., Matthews B., \& Zhang, Y. (2007). EEG-Based Estimation of Mental Fatigue: Convergent Evidence for a Three-State Model. In: D. D. Schmorrow, L. M. Reeves (Eds.), Foundations of Augmented Cognition (pp. 201-211). Heidelberg, Springer: Berlin. https://doi.org/10.1007/978-3-540-73216-7_23

[7] Homer, A. W. (2009). Coal Mine Safety Regulation in China and the USA. Journal of Contemporary Asia, 39(3), 424439. https://doi.org/10.1080/00472330902944511

[8] Bagherpour, R., Yarahmadi, R., \& Khademian, A. (2015). Safety Risk Assessment of Iran's Underground Coal Mines Based on Preventive and Preparative Measures. Human and Ecological Risk Assessment: An International Journal, 21(8), 2223-2238. https://doi.org/10.1080/10807039.2015. 1046418

[9] Piekarski, C., Seyl, G., \& Bardeleben, J. (1997). State of Miners' Health in Germany.Applied Occupational and Environmental Hygiene, 12(12), 815-819. https://doi.org/10.1080/1047322X.1997.10390615

[10] Konopko, W. (2013). Work safety in bituminous coal mines. Katowice: Główny Instytut Górnictwa.

[11] Sadłowska Wrzesińska, J., Gabryelewicz, I., \& Krupa, P. (2017). The use of IT tools for the analysis and evaluation of psychomotor efficiency of employees. MATEC Web of Conferences, 94,1-10. https://doi.org/10.1051/matecconf/ 20179406017

[12] Staniszewski, M., Legutko, S., Krolczyk, J. B., \& Foltys, J. (2018). The Model of Changes in the Psychomotor Performance of the Production Workers. Technical Gazette, 25(Supplement 1), 197-204. https://doi.org/10.17559/TV-20170223155120

[13] Eraslan, E., Can, G. F., \& Atalay, K. D. (2016). Mental workload assessment using a fuzzy multi-criteria method. Technical Gazette, 23(3), 667-674. https://doi.org/10.17559/TV-20140401112509

[14] Stasiuk Piekarska, A., Drzewiecka, M., \& Dahlke, G. (2014). Influence of macroergonomic factors on production systems organizing in automotive industry. In: P. Vink (ed.), Advances in social and organizational factors (pp. 194-205). USA: AHFE Conference.

[15] Butlewski, M., Dahlke, G., \& Drzewiecka, M. (2016). Impact of fatigue on selected psychomotor characteristics: A practical example (Dufour Cross-Shaped Apparatus). In: M.
A. Pedro et al. (Eds.), Occupational Safety and Hygiene IV (pp. 269-274). Great Britain: CPI Group, CRC Press.

[16] Dahlke, G., Drzewiecka, M., \& Butlewski, M. (2016). Impact of exposures to environmental factors on sense of balance stimulation. In: M. A. Pedro et al. (Eds.), Occupational Safety and Hygiene IV (pp. 243-248). Great Britain: CPI Group, CRC Press.

[17] Dahlke, G., Drzewiecka, M., \& Butlewski, M. (2016). Impact of the work process on power grip strength: A practical case. In: M. A. Pedroet al. (Eds.), Occupational Safety and Hygiene IV (pp. 237-242). Great Britain: CPI Group, CRC Press.

[18] Probst, G. J. \& Gomez, P. (1992). Thinking in Networks to Avoid Pitfalls of Managerial Thinking. In: M. Maruyama et al. (Eds.), Context and Complexity (pp. 91-108). New York: Springer. https://doi.org/10.1007/978-1-4612-2768-7_4

[19] Ziemniewicz, K. (2003). Modern concepts and methods of management. Warszawa: Polskie Wydawnictwo Ekonomiczne.

[20] Ragin-Skorecka, K., Grzelczak, A., Werner, K., \& Mroczek B. (2011). Building a network based on the factors affecting the innovative Wielkopolska. In M. Wyrwicka (Ed.), Budowa scenariuszy transformacji wiedzy wspierajacych innowacyjna Wielkopolske, Tom II (pp.77-113). Poznan: Wydawnictwo Politechniki Poznańskiej, Poznań.

[21] Piekarczyk, A. \& Zimniewicz, K. (2010). Network Thinking in Theory and Practice. Warszawa: Polskie Wydawnictwo Ekonomiczne.

[22] Górny, A. (2015). Man as internal customer for working environment improvements. Procedia Manufacturing, 3, 4700-4707. https://doi.org/10.1016/j.promfg.2015.07.565

[23] Grzelczak, A., Borowiec, A., \& Górny, A. (2013). Foresight for enterprises, Vol. II: Application of the network thinking methodology. Poznan: Wydawnictwo Politechniki Poznańskiej.

[24] Nowak, M., Mierzwiak, R., \& Butlewski, M. (2019). Occupational risk assessment with grey system theory. Central European Journal of Operations Research, 1-16.

[25] Norman, R. W. \& Wells, R. (1998). Ergonomic interventions for reducing musculoskeletal disorders: an overview, related issues and future directions. Royal Commission on Workers' Compensation in British Columbia

[26] Rothmore, P., Aylward, P., \& Karnon, J. (2014). Ergonomics and musculoskeletal injury prevention interventions in healthcare: are they worth it? Ergonomics Australia, 8, 1.

\section{Contact information}

\section{Marcin BUTLEWSKI}

(Corresponding author)

Faculty of Engineering Management,

Poznan University of Technology,

2 Prof. Rychlewskiego Str., 60-965 Poznan, Poland

marcin.butlewski@put.poznan.pl

\section{Grzegorz DAHLKE}

Faculty of Engineering Management,

Poznan University of Technology,

2 Prof. Rychlewskiego Str., 60-965 Poznan, Poland

\section{Milena DRZEWIECKA-DAHLKE}

Faculty of Engineering Management,

Poznan University of Technology,

2 Prof. Rychlewskiego Str., 60-965 Poznan, Poland

\section{Krzysztof HANKIEWICZ}

Faculty of Engineering Management,

Poznan University of Technology,

2 Prof. Rychlewskiego Str., 60-965 Poznan, Poland 
Adam GÓRNY

Faculty of Engineering Management

Poznan University of Technology,

2 Prof. Rychlewskiego Str., 60-965 Poznan, Poland

\section{Brigita GAJŠEK}

Faculty of Logistics, University of Maribor

Mariborska cesta 7, 3000 Celje, Slovenia

brigita.gajsek@um.si 